an inhibitory principle (factor $I)^{10}$. This effect is shown in Fig. 1. However, when $\gamma$-butyrobetaine and factor I are added together to the intestine bath, there is an enhancement of the contraction (Fig. 2). No evidence of an inhibitory effect of factor I on the contractions induced by $\gamma$-butyrobetaine similar to that observed with acetylcholine has ever been found. In those cases where a slow tonic contraction of the tissue succeeds the quick response, it appears that the potentiation due to factor $I$ is confined to the fast phase $^{10}$.

Thus, although the parallelism in action between $\gamma$-butyrobetaine and acetylcholine is close, it is not entirely general. Since the relationship between acetyleholine and factor I on the ileum of the guinea pig is not entirely clear, it is not possible to comment on the difference here observed with $\gamma$-butyrobetaine. The other pharmacological actions of $\gamma$-butyrobetaine can be satisfactorily explained by a prolonged action like that of acetylcholine.

Department of Biochemistry,

E. A. Hosern

McGill University, Montreal.

\title{
H. McLennan
}

Department of Physiology, University of British Columbia, Vancouver. Nov. 12.

${ }^{1}$ Keil, W., Linneweh, W., and Poller, K., Z. Biol., 86, 187 (1927).

${ }^{2}$ Hoppe-Seyler, F. A., and Schmidt, W., Z. Biol., 87, 69 (1927).

${ }^{3}$ Gulewitsch, W., and Krimberg, R., Z. physiol. Chem., 45, 326 (1905).

' Brieger, L., Eber Ptomaine, 3, 30 (1886).

'Takeda, K., Pflügers Arch. ges. Physiol., 133, 365 (1910).

${ }^{6}$ Reinwein, H., and Thielman, F., Arch. exp. path. Pharmakol., 103, 115 (1924).

'Linneweh, W., Z. physiol. Chem., 181, 42 (1929).

Hosein, E. A., Canad. J. Biochem. Physiol. (in the press).

- Brown, G. L., J. Physiol., 89, 220 (1937).

${ }^{10}$ Florey, E., and McLennan, H., J. Physiol. (in the press).

\section{Content of Deoxyribonucleic Acid of the Germinal Vesicle of the Primary Oocyte in the Rabbit}

BY means of centrifugation experiments, evidence of persistence of deoxyribonucleic acid in the growing nucleus of the primary oocyte was put forward by $J$. Brachet ${ }^{1}$. J. Govaert ${ }^{2}$ was able to demonstrate that, in Fasciola hepatica, the acid not only persists but also remains quantitatively constant in the germinal vesicle. The same quantitative constancy was later found by $J$. Mulnard ${ }^{3}$ to be existing in the oocytes of Acanthoscelides obtectus.

During our studies on content of deoxyribonucleic acid in the ovary of the rabbit, we tried to discover if this $\operatorname{sam} \theta$ constancy also occurs in this mammalian species. In the rabbit ovary, fixed in alcohol $(75$ parts), formalin (20 parts) and acetic acid (5 parts), the Feulgen reaction shows more or less visible chromosomal loops in the germinal vesicles of the oocytes, present in primary follicles (Figs. 1 and 2). This distribution, although not favourable, permits measurements by means of L. Lison's histophotometrical method4, so that a relative amount of deoxyribonucleic acid, expressed in arbitrary units, can be obtained and compared with a standard value, given by the mean acid content of spermatocytes I measured in a rabbit testis under identical experimental conditions. The mean content of deoxyribonucleic acid for 107 measured oocytes was $2,400 \pm 50 \cdot 2(S=523 \cdot 7)$, while for 301 spermatocytes I we obtained $2,393 \pm 26 \cdot 8(S=465 \cdot 4)$.

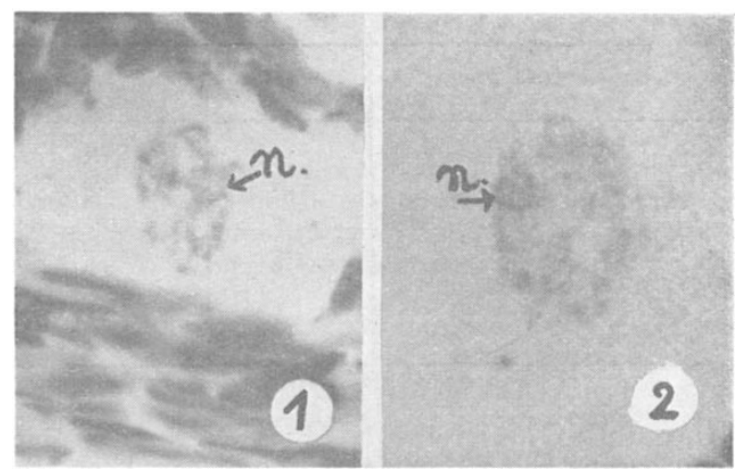

Figs. 1 and 2. Demonstration of the youngest (1) and oldest (2) measured germinal vesicles, stained by the Feulgen reaction. Statistical computation shows that, so far as their content of deoxyribonucleic acid is concerned, the nuclei between those two limits belong to the same population ( $n$, nucleolus, surrounded by a ring of nucleolus-associated chromatin)

The distribution of deoxyribonucleic acid found in those young germinal vesicles seemed to permit only the demonstration of an order of magnitude.

These results suggest that in the rabbit oocyte I, the content of deoxyribonucleic acid corresponds to the theoretically expected content (4n, as in the spermatocytes I). Moreover, this content remains unchanged at least during the formation of the young germinal vesicle, up to the stage measured here.

This research was supported by a grant of the Belgian F.N.R.S.

\section{VAN DE KERCKHOVE}

Department of Normal and Comparative Anatomy, Belgian Centre of Normal and Pathological Growth, University of Ghent.

$$
\text { Nov. } 13 .
$$

I Brachet, J., "Embryologie chimique" (Desoer, Liège, 1944).

2 Govaert, J., Nature, 172, 302 (1953).

s Mulnard, J., Arch. Biol., 65, 261 (1954)

${ }^{4}$ Lison, L., Acta Anat., 10, 333 (1950).

\section{Liver Hexokinase Activity in Rats adapted to Intermittent Starvation}

FABRY's experiments ${ }^{1}$ which were performed in this laboratory have shown that, in rats adapted to intermittent starvation, more glycogen is deposited in the liver after the intake of an equal amount of a mixed diet than in rats fed normally. We may thus expect that in these animals there devolops an adaptation of the enzymes participating in glycogen synthesis. We have therefore attempted to estimate the liver hexokinase activity, because this enzyme has a key position in the synthesis of glycogen.

We used female Wistar rats with an initial weight of about $100 \mathrm{gm}$. During the experiment the animals were kept at a temperature of $21-23^{\circ} \mathrm{C}$. During the six-week period of adaptation to intermittent starva. tion we interposed gradually longer fasts between the days when the animals had free access to food. During the last week of adaptation the animals were fed only twice ${ }^{1}$. The total food consumption in the adapted animals amounted to 60 per cent of the intake of control animals fod ad lib. Throughout the experimental period the animals had free access to water. The rats were fed on a stock diet (Larsen's diet) providing about 25 cal. per cent protein, 25 cal. per cent fat and $50 \mathrm{cal}$. per cent carbohydrate. 